\title{
Determination of the Kinetic Behavior of Diclofenac in Aqueous Solution by UV Light Radiation
}

\author{
M. E. Becerril • J. J. Ramírez-García • N. Cavazos •
}

\section{A. Ramírez Serrano}

Received: 12 April 2019/Accepted: 16 August 2019

(C) Springer Nature Switzerland AG 2019

\begin{abstract}
Diclofenac (DCF) is one of the most widely used non-steroidal anti-inflammatory drugs worldwide, and several studies have reported adverse effects on the environment, in plants and animals; so, it is classified as an emerging pollutant. There are several alternatives for its removal; however, it is necessary to study the way in which the DCF is degrading to offer more effective removal techniques, since the traditional ones such as chlorination, activated sludge, and biofiltration offer low removal efficiency (20-40\%). This work analyzes the kinetic behavior of the photodegradation of DCF and the thermodynamic parameters of the reaction under UV-C-type light radiation. The results obtained indicate that it presents a first-order kinetic promoted by the increase of the temperature. Also, within the evaluated
\end{abstract}

M. E. Becerril · J. J. Ramírez-García $(\bowtie) \cdot$ A. R. Serrano Facultad de Química, Universidad Autónoma del Estado de México, Paseo Colón esq. Paseo Tollocan S/N, C.P. 50120 Toluca, Edo. de Méx., Mexico

e-mail: jjramirezg@uaemex.mx

M. E. Becerril

e-mail: maeugeniabo@gmail.com

A. R. Serrano

e-mail: aramirezs75@hotmail.com

N. Cavazos

Facultad de Medicina, Departamento de Química Analítica, Universidad Autónoma de Nuevo León, Avenida Madero y Dr. Eduardo Aguirre Pequeño S/N Col, Mitras Centro, C.P.64460 Monterrey, Nuevo León, Mexico

e-mail: nocavazos@yahoo.com interval ( 273 to $308 \mathrm{~K}$ ), the values of the kinetic coefficient $(k)$ range between 0.05 and $0.20 \mathrm{~min}^{-1}$ and the half-life ranges from 3 to $9 \mathrm{~min}$. The reaction is exothermic and spontaneous and gives way to the formation of approximately 6 byproducts, being two with the greatest presence and stability. This suggests that its decomposition route occurs through the dechlorination of the molecule and originate compounds known as carbazoles that have been detected in previous works. It was also found that this mixture of byproducts remained after the degradation of the drug, which is released to the environment, so it is necessary to extend a study on its properties and its possible environmental impact.

Keywords Photodegradation $\cdot$ Drug $\cdot$ Half-life .

Diclofenac

\section{Introduction}

There is currently a growing concern about the continued presence of pharmaceutical products in the environment because a negative impact on plants and animals has been detected. The drugs are introduced into the aquatic effluents through their transport in wastewater containing excretes from people who have used them, residues of medicines that were handled improperly, or through agricultural residues, such as livestock manure (Alalm et al. 2015).

This has caused plants and animals to be continuously in contact with this type of compounds causing 
alterations in their normal cycle of growth and reproduction (Cooper and Song 2007; Orepesa 2008).

Several studies have evaluated the prolonged exposure of pharmaceutical contaminants in animals and plants, obtaining results that show toxic effects on them as endocrine modifications, cytotoxicity, teratogenesis, and inhibition of their growth (Garima and Sindri 2017; Jiménez 2011; Melo et al. 2014; Rainsford et al. 2008; Wang and $\mathrm{Hu}$ 2014). The previous arguments have given a guideline to classify drugs as emerging contaminants.

Diclofenac has been frequently detected in wastewater effluents at concentrations around $1 \mu \mathrm{g} \mathrm{L}^{-1}$ (Alharbi et al. 2017; Garima and Sindri 2017) and its adverse effects have been reported after a short-term exposure to several aquatic species including algae, crustaceans, bivalves, and some species of fish such as rainbow trout and zebrafish (Garima and Sindri 2017; Lonappan et al. 2016; Magureanu et al. 2015; Memmert et al. 2013). In the rainbow trout, it was observed that a concentration of $1 \mu \mathrm{g} \mathrm{L}^{-1}$ generates alterations at the cellular level (Köhler et al. 2004) and in several exposure studies at $48 \mathrm{~h}$, high mortality of aquatic fauna was observed, with maximum mean effective concentration values $\left(\mathrm{EC}_{50}\right)$ from 22.4 to $39.9 \mathrm{mg} \mathrm{L}^{-1}$ (Ferrari et al. 2003).

Other similar assessments show degenerative impacts on the structure and functions of aquatic organisms at lower concentrations of $100 \mathrm{ng} \mathrm{L}^{-1}$ (Lawrence et al. 2007).

The presence of DCF in residual effluents is the result of the high consumption of drugs with this active principle and the low removal efficiency (20-40\%) (Magureanu et al. 2015) that traditional treatments for wastewater have, such as chlorination, activated sludge, or other forms of biological treatment such as biofiltration (Vieno et al. 2006). It is estimated that around 10,000 tons/year are consumed worldwide and these correspond to formulations for human and veterinary use (Memmert et al. 2013).

The existing conventional water treatment plants were not designed for this type of contaminants, so it is necessary to develop proposals with processes and treatment techniques to eliminate drugs. Currently, processes include advanced oxidation process (AOPS) such as the use of UV light, $\mathrm{H}_{2} \mathrm{O}_{2}$, or physical (zeolite) and electrochemical methods that have shown high removal rates. However, they do not consider the formation of byproducts that can be stable and have a higher toxicity index than the drug in aqueous medium. Knowing the degradation profile of the drug, the instability or resistance of this and its byproducts can be evidenced, its percentage of decomposition can be predicted, and its half-life estimated. So, it is necessary to establish the behavior of the degradation kinetics considering the formation of byproducts. The kinetic behavior of DCF has been reported in other studies (Hashim et al. 2014; Kovacic et al. 2016; Zhang et al. 2017). The latter being the specific time it takes for the present amount of the compound to be reduced by half (Gidal et al. 2017). Obtaining the above data for diclofenac, the kinetic behavior of the active agent was determined before photolysis, the stability of its byproducts and its percentage of degradation.

\section{Methodology}

\subsection{Chemicals}

The chemicals include Diclofenac standard (DCF) Sigma Aldrich brand, deionized Milli Q water from Millipore, acetonitrile $(\mathrm{ACN})$ brand J.T. Baker grade HPLC, and formic acid (AF) Fermont brand (reactive grade, $98 \%$ ).

\subsection{Photodegradation}

A device consisting of a batch reactor equipped with a UV-C-type monochromatic lamp of $15 \mathrm{~W}$ with a fixed wavelength $(254 \mathrm{~nm})$ was used with a reflux system to maintain the constant temperature and a magnetic stirring grid. The reactor was isolated from outside light. Figure 1 shows the diagram of the system used. The experiment was carried out by subjecting an aqueous solution of $10 \mathrm{mg} \mathrm{L}^{-1}$ of DCF under ultraviolet light radiation $(254 \mathrm{~nm})$ at three different temperatures of 278, 288, and $298 \mathrm{~K}$ with constant magnetic stirring. The samples collected were analyzed immediately after having been exposed to UV-C light radiation for a certain time.

\subsection{Analysis}

Aliquots of the irradiated solution were taken at different time intervals to evaluate the change in the initial concentration and evidence the formation of their degradation products. Before to their analysis, the samples were filtered using nylon acrodys with a pore size of $0.45 \mu \mathrm{m}$. The quantitative analysis was performed using a 
Fig. 1 UV light degradation equipment. (a)Water bath for temperature control. (b) Lamp. (c) Dark chamber. (d) Grill for magnetic stirring. (e) and (f) Water outlet and inlet. Sample (g)

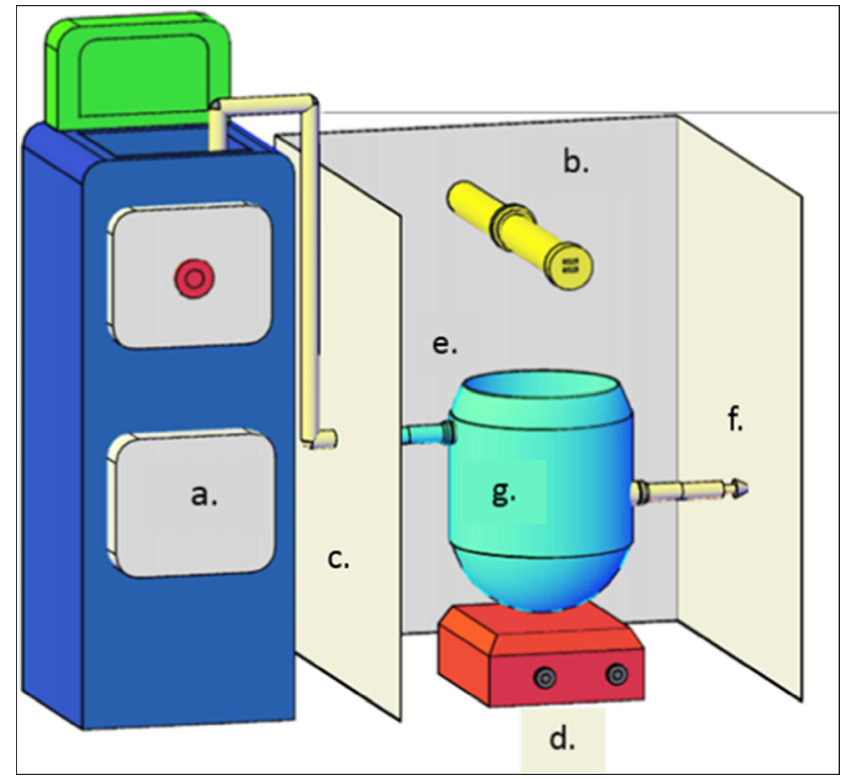

validated analytical method of high-performance liquid chromatography (HPLC) in a Waters brand equipment with UV detector model 2487 (dual ABS) and 515 model pump with isocratic flow and an Eclipse XDBC18 $5 \mu \mathrm{m} 4.6 \times 250 \mathrm{~mm}$; using as mobile phase a solution of acetonitrile (ACN): formic acid (AF) $0.1 \%$ (v/ v) 70:30 at a flow of $1.0 \mathrm{~mL} \mathrm{~min}^{-1}$, the injection volume of the samples was $10 \mu \mathrm{L}$; it worked at room temperature and the detection was at a wavelength of $280 \mathrm{~nm}$.

\subsection{Kinetic Evaluation of Photodegradation}

The data obtained from the photodegradation experiment and the quantification by the chromatographic method were treated considering the system as a batch reactor with homogeneous agitation, volume, and constant temperature, to obtain the parameters that describe the rate reaction equation following:

$r_{\mathrm{A}}=\frac{d C_{\mathrm{DCF}}}{d t}=-k C_{\mathrm{DCF}}^{\alpha}$

where $r_{\mathrm{A}}$ is the rate reaction, $C_{\mathrm{DCF}}$ is the concentration of diclofenac, $t$ is the time, $k$ is the kinetic coefficient of the reaction rate, and $\alpha$ the reaction order.

\section{Results and Discussion}

\subsection{Effect of UV-C Light Radiation in DCF}

The photodegradation experiments were carried out using a $10 \mathrm{mg} \mathrm{L}^{-1}$ solution exposed to ultraviolet light radiation using a wavelength of $254 \mathrm{~nm}$ at three different temperatures (278, 288, and $298 \mathrm{~K})$. Additionally, an experiment at temperature of $298 \mathrm{~K}$ without exposure to radiation was carried, which was considered as a target to verify if the degradation of the drug occurs due to the effect of the radiation and not to the hydrolysis or some environmental factor not considered within the evaluation of the results.

The degradation profile of the DFC at different temperatures is shown in Fig. 2. In this graph, it is observed that at the temperature of $298 \mathrm{~K}$, the change in the concentration of DCF occurred during the first $10 \mathrm{~min}$ of exposure to radiation and after this time the concentration remained constant, reaching a degradation percentage of approximately $90 \%$.

In the case of profiles of temperatures of 288 and 278 $\mathrm{K}$, the degradation process occurred less quickly, in the first $10 \mathrm{~min}$ the percentage for $288 \mathrm{~K}$ was only $55 \%$ and for 278 of $45 \%$, reaching the $90 \%$ up to almost $30 \mathrm{~min}$.

Both temperatures had a similar behavior, and during the first $15 \mathrm{~min}$, they showed a continuous concentration change; after this time, the change was to a lesser 
Fig. 2 DCF Degradation profile by $\mathrm{UV}-\mathrm{C}$ radiation effect

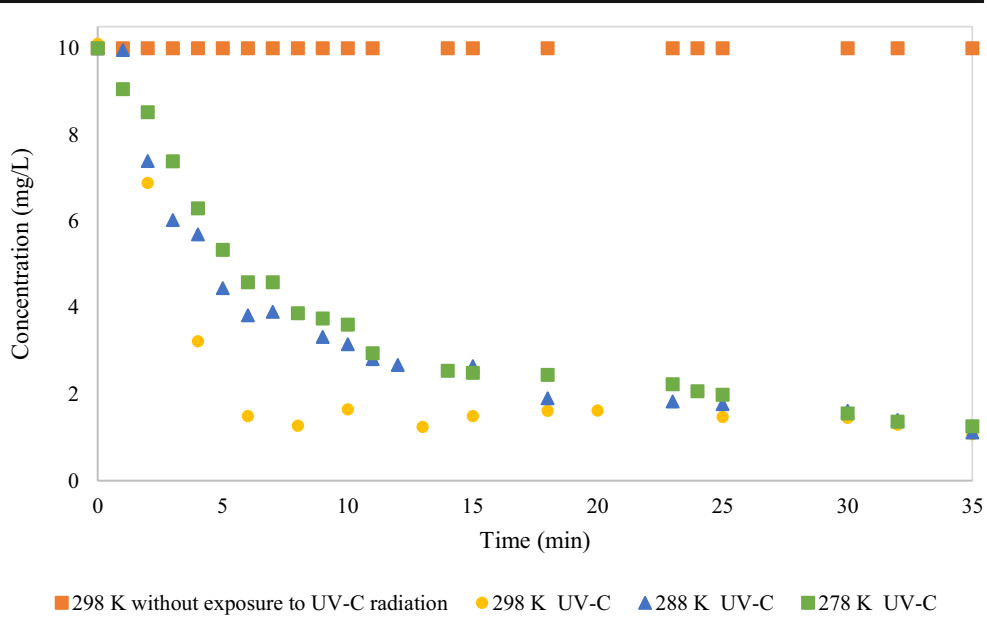

degree. The aformentioned shows that DCF degradation is susceptible to temperature.

Around $30 \mathrm{~min}$ after, the three temperatures reached the same concentration ( $90 \%$ of drug degradation), point that could indicate the temperature does not influence and the equilibrium of the reaction has been reached.

In the case of the profile defined as control, during the time of exposure, there was no change in the concentration of the compound indicating that the degradation was caused by exposure to UV-C type radiation.

It was also observed that during the experiment, the appearance of the solutions were gradually changing to a yellow color, this being indicative of the presence of degradation products derived from the decomposition. The above did not occur in the solution indicated as control; being provided as additional test to confirm that the DCF is susceptible to the effects of UV-C type radiation. Figure 3 illustrates the initial and final appearance of the irradiated solution, this agrees with that reported in photolysis work of DCF with sunlight and UV-C light radiation (Eriksson et al. 2010; Keen et al. 2013).

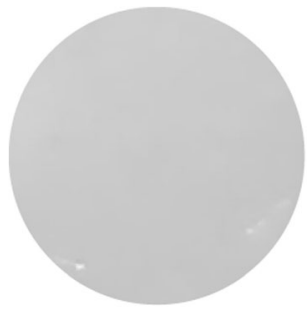

a)

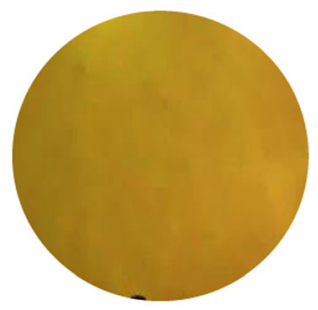

b)
Fig. 3 DCF solution before (a) and after (b) of UV-C light irradiation

\subsection{DCF Kinetic Photodegradation Model}

Aliquots of the irradiated solution were taken at different time intervals to evaluate the change in the initial concentration of the DCF solution by quantifying the samples with the previously described analytical method.

To determinate the order of photodegradation rate for DCF, the concentration values found at different times were used and were treated using the integral method (Scott Fogler 2002).

The results obtained indicate that a first-order kinetic model describes the profile of the concentration changes; this is consistent with previous work where the photodegradation kinetics for DCF has also been studied (Hashim et al. 2014; Kovacic et al. 2016; Zhang et al. 2017). The mathematical representation is shown below:

$\ln \frac{C_{\mathrm{DCF} 0}}{C_{\mathrm{DCF}}}=k t$

where $C_{\mathrm{A}}$ is the DCF concentration, $C_{\mathrm{A} 0}$ is the initial DCF concentration, $t$ is the time, and $k$ is the kinetic coefficient of the reaction rate.

The order obtained indicates that the rate of degradation is directly proportional to the concentration, causing that the variation of the drug over time depends directly on the value of the kinetic coefficient of the reaction, as indicated in Eq. (2).

This type of order is characteristic of decomposition, degradation, or isomerization reaction (Scott Fogler 2002).

The direct dependency to the kinetic coefficient shows that with the increasing or decreasing the rate of 
degradation, its value must be modified. According to the Arrhenius equation, the value of this constant depends directly on the activation energy of the reaction and the temperature, so DCF degradation will be affected by these two factors directly.

Figure 4 describes the concentration profile with respect to time considering that the reaction is of first order for the three temperatures evaluated $(298,288$, and $278 \mathrm{~K}$ ), determining the variation of the concentration change rates and the kinetic coefficient for each temperature. The latter was obtained from the slope of the linear regression of plot. The calculated values were $0.16 \mathrm{~min}^{-1}$ at $298 \mathrm{~K}, 0.11 \mathrm{~min}^{-1}$ at $288 \mathrm{~K}$, and $0.084 \mathrm{~min}^{-1}$ for $278 \mathrm{~K}$. The above indicates an increase in the constant, causing the degradation to occur in less time to increase the value of this parameter in the irradiated solution, as it occurs in the degradation profile shown in Fig. 2.

\subsection{DCF Kinetic Parameters}

Based on the Arrhenius equation (Scott Fogler 2002), linear regression was performed for the determination of kinetic parameters where the activation energy is $22.05 \mathrm{~kJ} \mathrm{~mol}^{-1}$ and the frequency factor is $1.15 \mathrm{~min}^{-1}$ respectively. Next, the mathematical model used is shown:

$\ln k=\ln A-\frac{E a}{R}\left(\frac{1}{T}\right)$

where $k$ is the kinetic coefficient, $A$ is the frequency factor $\left(\mathrm{min}^{-1}\right)$, Ea is the activation energy $(\mathrm{J} / \mathrm{mol})$, and $T$ is the absolute temperature in degrees Kelvin.

This equation was used to analyze the effect of temperature on the rate of degradation reaction rate (Scott

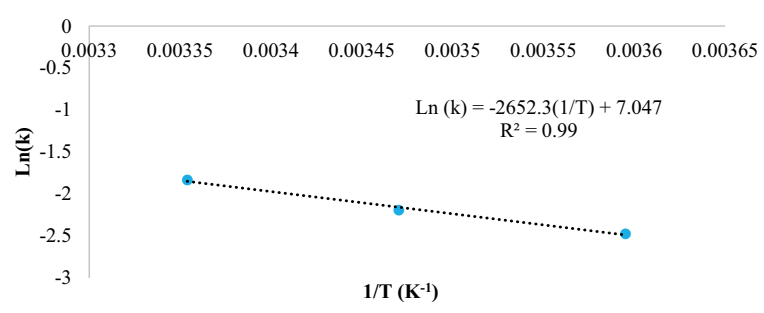

Fig. 5 Linear regression of the Arrhenius equation

Fogler 2002). Figure 5 shows the graph of the linear regression of the Arrhenius equation for DCF.

Using the values of Ea and $A$ obtained, the simulation of the photodegradation profile was performed (Fig. 6) within the range of 273 to $308 \mathrm{~K}$. Subsequently, the apparent kinetic coefficient (Fig. 7) and the half-life at different temperatures were evaluated (Fig. 8). With the kinetic model shown in Fig. 6, the photodegradation behavior is presented, where the reduction of the concentration is favored with the increase of the temperature and the reaction rate. During the first $30 \mathrm{~min}$, the DCF is affected by the temperature and the change in concentration will depend on the value of it. It is observed that after approximately $40 \mathrm{~min}$, the concentration values are similar for all the temperatures evaluated, and around $60 \mathrm{~min}$ when the minimum concentration is reached for all the profiles and the degradation speed is no longer dependent on the temperature, confirming that the reaction at this point reaches equilibrium.

It was found that within the evaluated temperature range, the values of the kinetic coefficient $(k)$ oscillate between 0.05 and $0.20 \mathrm{~min}^{-1}$, showing that at a lower temperature the speed of the reaction will occur more slowly, and at high temperature the degradation will be favored. The behavior of the values of the constant proves that the temperature directly influences the
Fig. 4 DCF degradation kinetics $\left(\mathrm{CDCF} 0=10 \mathrm{mg} \mathrm{L}^{-1}\right)$

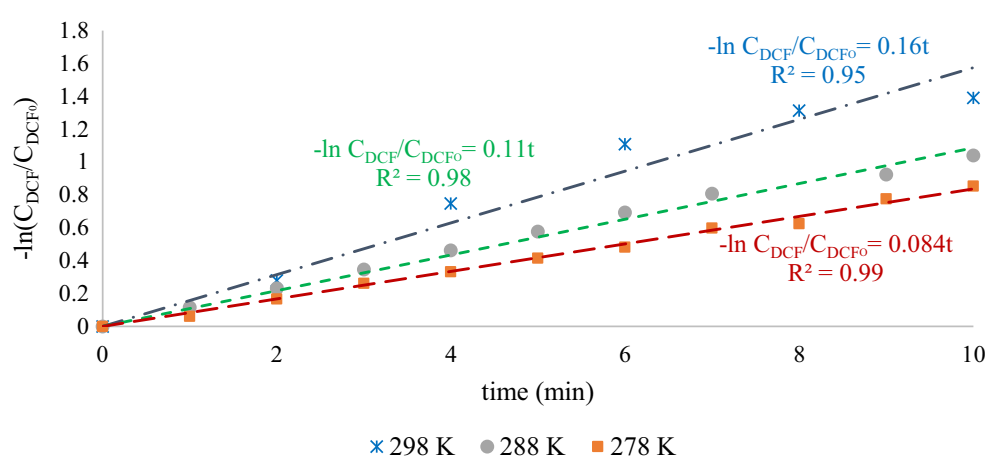


Fig. 6 DCF kinetic simulation behavior photodegradation at different temperatures

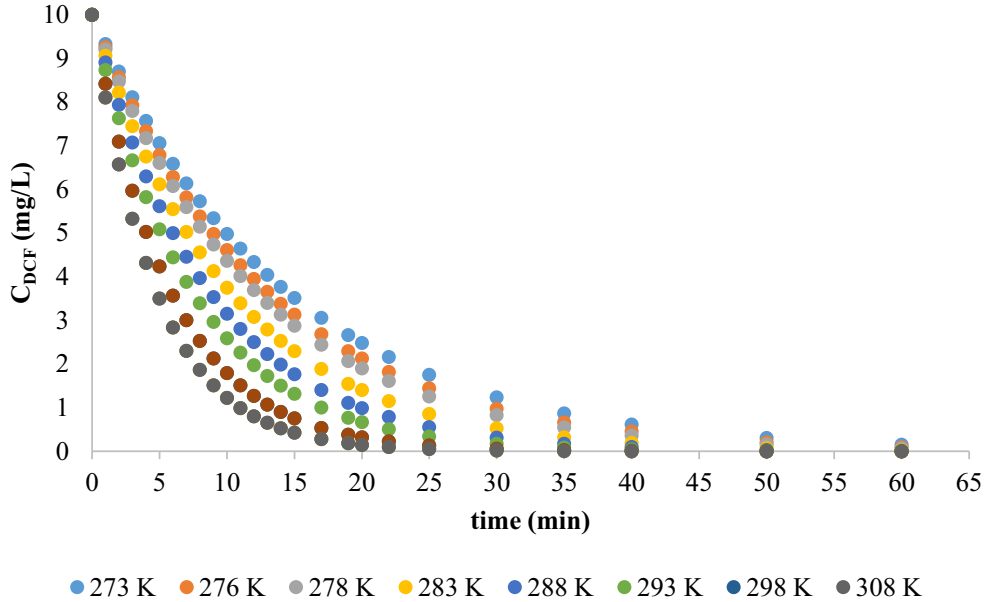

degradation. (Fig. 7). The half-life profile $\left(t_{1 / 2}\right)$ was obtained considering a first-order reaction and a concentration corresponding to half the initial concentration. The equation used is shown below:

$t_{1 / 2}=\ln [0.5]\left[\frac{1}{k}\right]$

where $t_{1 / 2}$ is the DCF half-life (min) and $k$ is the kinetic coefficient $\left(\mathrm{min}^{-1}\right)$.

The values found for the half-life range from approximately 3 to $9 \mathrm{~min}$, this is due to the fact that the increase in the value of the coefficient is favored (Fig. 8). The above suggests that at low temperatures, the DCF is more stable and at higher temperatures it degrades more easily. The short half-life of the drug suggests that there is a greater probability that it is present in a lower proportion than the initial concentration when exposed to UV-C radiation, and that it is more likely to be located

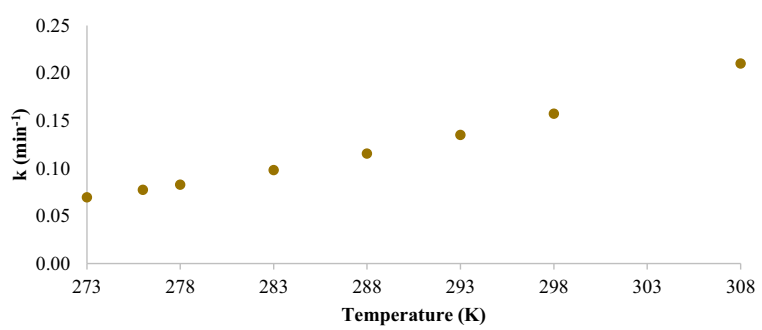

Fig. 7 Simulation behavior of photodegradation kinetic coefficient $(k)$ as a mixture of byproducts derived from its degradation. Table 1 shows the values of the parameters evaluated.

\subsection{Thermodynamic Parameters of DCF Photodegradation}

The values of the kinetic coefficient $(k)$ obtained using the van't Hoff linearized equation, the enthalpy $\left(\Delta H^{\circ}\right.$, $\mathrm{kJ} / \mathrm{mol})$, and entropy $\left(\Delta S^{\circ}, \mathrm{kJ} / \mathrm{mol} \mathrm{K}\right)$ were evaluated obtaining values of $-22.03 \mathrm{~kJ} / \mathrm{mol}$ and $0.058 \mathrm{~kJ} / \mathrm{mol} \mathrm{K}$ respectively (Fig. 9). The mathematical model is shown below:

$\ln (k)=\frac{\Delta H^{\circ}}{R}\left(\frac{1}{T}\right)+\frac{\Delta S^{\circ}}{R}$

where $\Delta H^{\circ}$ and $\Delta S^{\circ}$ are the enthalpy and entropy change; $T$ is the absolute temperature in Kelvin; $R$ is the ideal gas constant $\left(8.314 \times 10^{-3} \mathrm{~kJ} / \mathrm{mol} \mathrm{K}\right)$; and $k$ is the kinetic coefficient.

The enthalpy and entropy values were used to calculate the free energy of Gibbs $(\Delta G, \mathrm{~kJ} / \mathrm{mol})$ in the temperature interval from 273 to $308 \mathrm{~K}$, with the help of the following equation:

$\Delta G^{\circ}=\Delta H^{\circ}-T \Delta S^{\circ}$

where $\Delta H^{\circ}, \Delta S^{\circ}$, and $\Delta G^{\circ}$ are the enthalpy, entropy, and free energy of Gibbs change and $T$ is the absolute temperature in Kelvin. 
Fig. 8 Behavior of the half-life at different temperatures

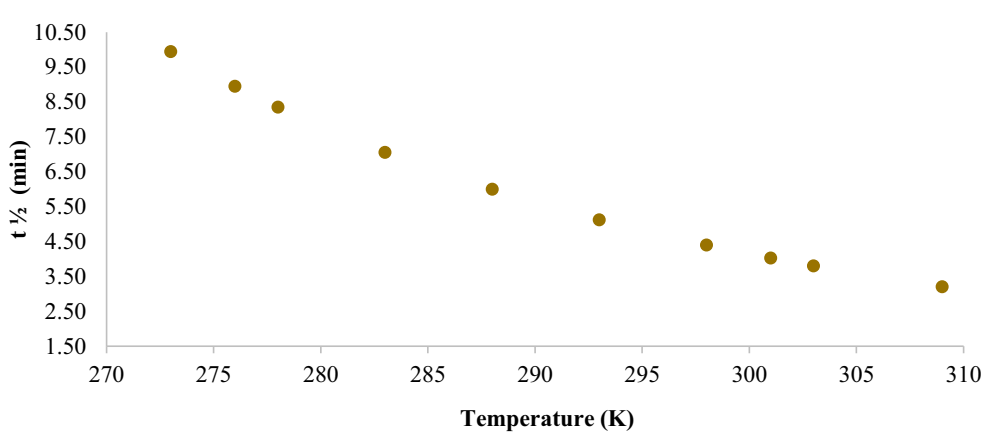

The thermodynamic behavior of the photodegradation reaction indicates that it is exothermic (negative value of enthalpy) and occurs spontaneously and irreversibly (indicated by the positive value of the entropy and Gibbs free energy). In previous studies with DCF solar radiation, similar behavior was also found (Zhang et al. 2017).

\subsection{Photodegradation Products}

Of the photodegradation experiments carried out, the formation of approximately six byproducts was detected during exposure to UV-C radiation (Fig. 10). Considering the number of compounds found and the color change illustrated in Fig. 3, the possible route by which the drug is being degraded is the formation of dimers classified as carbazoles (Keen et al. 2013; Kovacic et al. 2016; Qin et al. 2012); these are compounds that give way to a yellowish solution and its structure is composed of aromatic rings that derive from the union of the rings of the DCF molecule (Keen et al. 2013).

It has been indicated that due to the chemical structure of the DCF (Fig. 11), the cleavage of the two chlorine atoms is favored during the photodegradation process giving way to the union of their aromatic rings originating the carbazoles (Keen et al. 2013).

Taking into account what has been reported in works of similar experiments, the major products $\mathrm{P} 1$ and $\mathrm{P} 2$ found are derived from the consecutive loss of the two chlorines of the DCF molecule, and could be compounds called carbazole 1 (8-chloro-9H-carbazole). -1il) acetic acid and carbazole 2 (8-hydroxy-9H-carbazol1 -yl) acetic acid, found in various studies with solar radiation (Eriksson et al. 2010; Kovacic et al. 2016) and byproducts $\mathrm{P} 3, \mathrm{P} 4, \mathrm{P} 5$, and $\mathrm{P} 6$ correspond to structures derived from the disintegration of these two molecules that give way to the formation of more carbazoles or aldehyde derivatives (Eriksson et al. 2010).

Figure 12 a shows the chromatogram of the initial solution, having a retention time $\left(t_{\mathrm{R}}\right)$ around $5 \mathrm{~min}$. After $1 \mathrm{~h}$ of exposure to UV-C radiation in Fig. $12 \mathrm{~b}$, the appearance of new signals with a retention time lower than the DCF ( $t_{\mathrm{R}}$ approximately 2 to $3 \mathrm{~min}$ ), which correspond to degradation products, is observed from DCF degradation. As time passes, it can be observed in Fig. $12 \mathrm{c}$ and $\mathrm{d}$ that the new signals increase in intensity. Therefore, the increase in their concentration occurs. This indicates that despite the fact that the asset has been degraded around $90 \%$ during the first hour, $10 \%$ of the remaining solution consists of a mixture of the drug (40\%) with its byproducts $(60 \%)$.

The increase and decrease in the area of the different signals other than DCF in the chromatograms, possibly due to the instability of the various compounds, lead to the formation of new products. These changes have been reported as secondary reactions that result in compounds called carbazoles (Agüera et al. 2005; Eriksson et al. 2010).

Table 1 DCF kinetic parameters

\begin{tabular}{|c|c|c|c|c|c|c|c|c|c|c|}
\hline Temperature (K) & 273 & 276 & 278 & 283 & 288 & 293 & 298 & 301 & 303 & 308 \\
\hline$k\left(\min ^{-1}\right)$ & 0.07 & 0.08 & 0.08 & 0.10 & 0.12 & 0.14 & 0.16 & 0.17 & 0.18 & 0.21 \\
\hline Half-life (min) & 9.95 & 8.95 & 8.35 & 7.06 & 6.00 & 5.13 & 4.41 & 4.03 & 3.80 & 3.30 \\
\hline
\end{tabular}




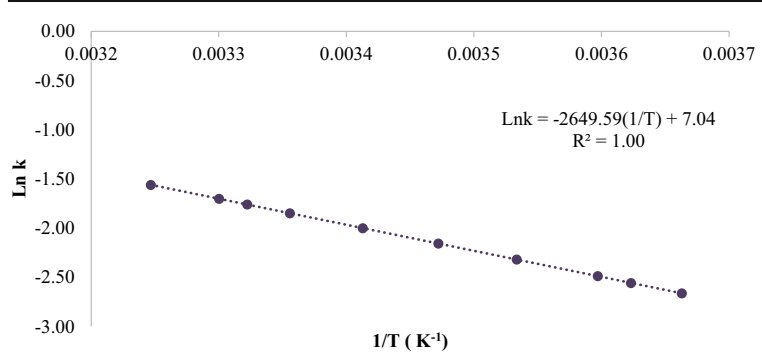

Fig. 9 Linear regression of the van't Hoff equation

The constant presence of byproducts beyond the halflife of DCF (approximately 4 min at $298 \mathrm{~K}$ ) suggests that some of these compounds are stable to UV-C radiation. In Fig. 10, the behavior of its formation and degradation during the first $48 \mathrm{~h}$ is described, it can be noted that the products $\mathrm{P} 1$ and $\mathrm{P} 2$ are the first to appear and tend to remain throughout the irradiation time. After the first $2 \mathrm{~h}$, the presence of new secondary compounds begins to be more considerable, with the $\mathrm{P} 3$ product being one of the first to manifest itself, but to a lesser extent than the P1. The P4 product appears in the first minutes and does not disappear, it only varies in the proportion corresponding to the formation of the other species, and this compound has a lower presence compared with the other products. The P5 compound as P4 varies its proportion and from the first $2 \mathrm{~h}$, its presence increases. The P6 product increases after $4 \mathrm{~h}$ and remains one of the major byproducts throughout the remaining period. At the end, we obtain a solution composed of two major products $\mathrm{P} 1$ and $\mathrm{P} 6$, which may correspond to one of the carbazoles reported in previous research (Bartels and von Tümpling 2007; Eriksson et al. 2010; Keen et al. 2013).

Having carbazoles resistant to photolysis in the final mixture implies the probability that these will be released into the environment; so, it is necessary to extend

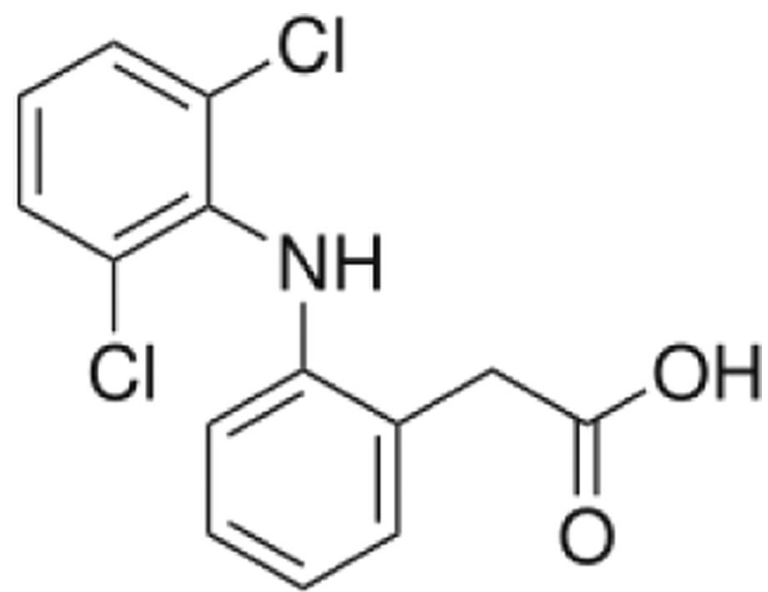

Fig. 11 Chemical structure of diclofenac

a study on its properties and its possible environmental impact. Evidence has been found that some compounds of this type tend to bioaccumulate and have caused toxic effects in some aquatic species (Chittim et al. 2016; Salam et al. 2017).

Currently, drug removal alternatives focus only on the asset and not on its degradation products. However, due to the above results, it can be mentioned that options for the management or inactivation of the degradation products must be included since it is very probable to find the presence of these compounds during the treatments of removal of this drug or that some of them have toxic properties.

\section{Conclusions}

The photodegradation reaction of DCF by UV-C radiation is a first order and is promoted by the increase of temperature.
Fig. 10 Behavior of DCF degradation products

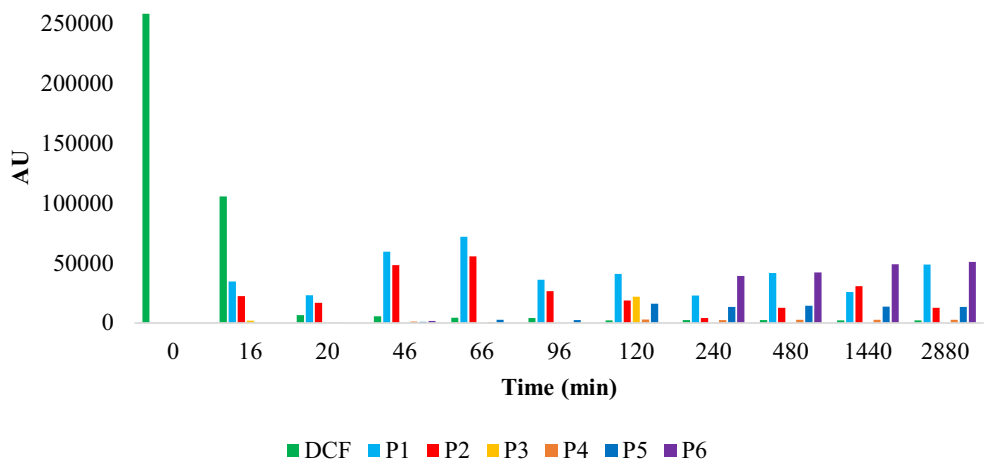


Water Air Soil Pollux $\quad$ (2019) 230:219

Page 9 of 11219
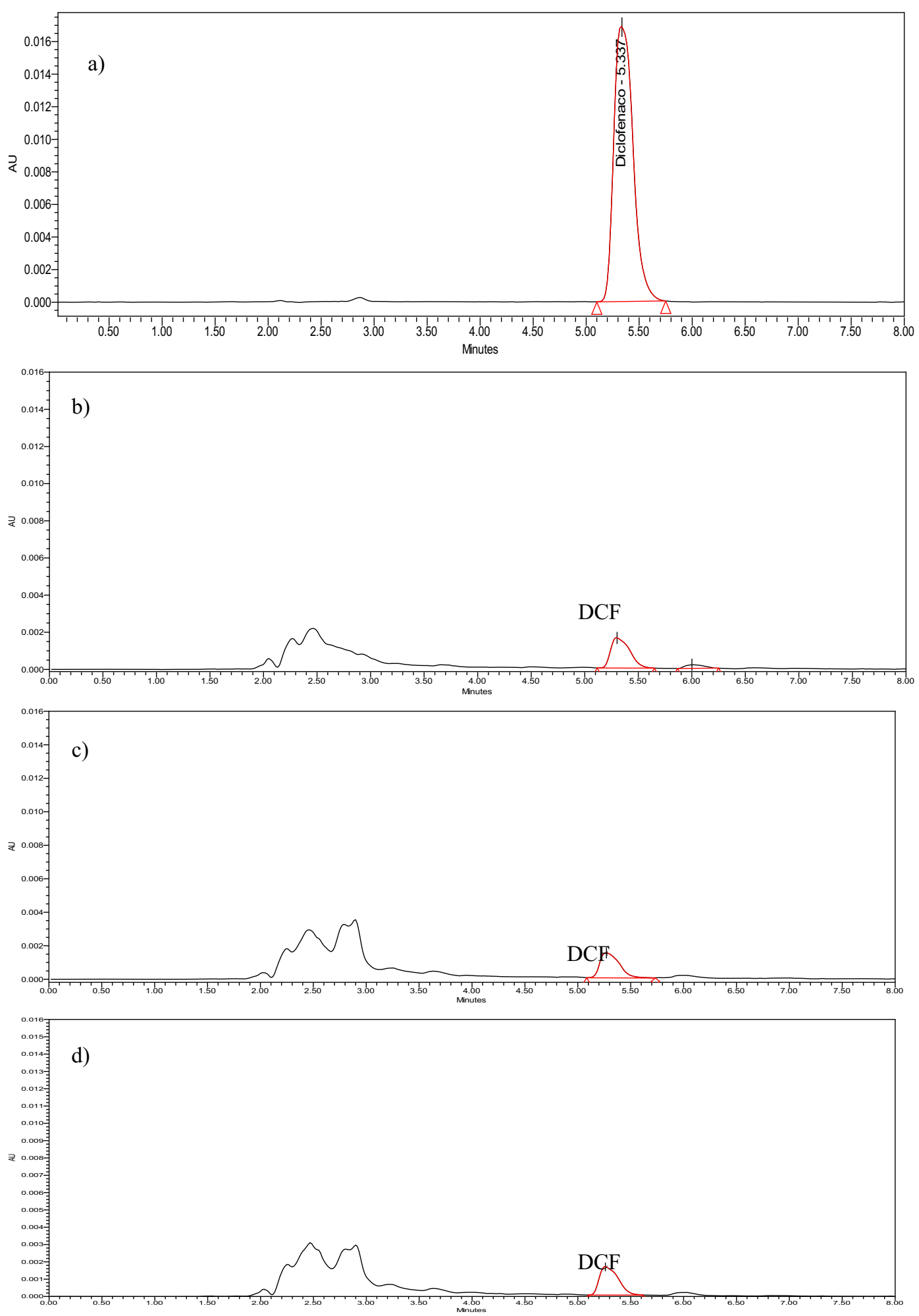

Fig. 12 Degradation products chromatogram at (a) initial, (b) 1 h, (c) 24 h, (d) $48 \mathrm{~h}$ after exposure to UV-C radiation

Springer 
The kinetic parameters were simulated as a function of temperature (273-308 K) and it was found that the average life of this drug ranges from 3 to $9 \mathrm{~min}$. The thermodynamic parameters obtained indicate that its photodegradation occurs exothermically in a spontaneous and irreversible reaction. The degradation of DCF forms stable byproducts that tend to be present even after the DCF degradation and possibly correspond to a mixture of compounds called carbazoles derived from diclofenac dechlorination.

Funding Information The authors received financial support from CONACYT (Project 215997) and CONACYT scholar grant no. 8060728 for María Eugenia Becerril Ortiz.

\section{References}

Agüera, A., Perez Estrada, L. A., Ferrer, I., Thurman, E. M., Malato, S., \& Fernandez-Alba, A. R. (2005). Application of time-of-flight mass spectrometry to the analysis of phototransformation products of diclofenac in water under natural sunlight. Journal of Mass Spectrometry, 40(7), 908915. https://doi.org/10.1002/jms.867.

Alalm, M. G., Tawfik, A., \& Ookawara, S. (2015). Degradation of four pharmaceuticals by solar photo-fenton process: kinetics and costs estimation. Journal of Environmental Chemical Engineering, 3(1), 46-51. https://doi.org/10.1016/j. jece.2014.12.009.

Alharbi, S. K., Kang, J., Nghiem, L. D., van de Merwe, J. P., Leusch, F. D. L., \& Price, W. E. (2017). Photolysis and UV/ $\mathrm{H} 2 \mathrm{O} 2$ of diclofenac, sulfamethoxazole, carbamazepine, and trimethoprim: Identification of their major degradation products by ESI-LC-MS and assessment of the toxicity of reaction mixtures. Process Safety and Environmental Protection, 112, 222-234. https://doi.org/10.1016/j.psep.2017.07.015.

Bartels, P., \& von Tümpling, W. (2007). Solar radiation influence on the decomposition process of diclofenac in surface waters. Science of the Total Environment, 374(1), 143-155. https://doi.org/10.1016/j.scitotenv.2006.11.039.

Chittim, B., Helm, P. A., Safe, S., Poirier, D., Riddell, N., Ruffolo, R., et al. (2016). Environmental levels and toxicological potencies of a novel mixed halogenated carbazole. Emerging Contaminants, 2(3), 166-172. https://doi. org/10.1016/j.emcon.2016.07.002.

Cooper, William J., \& Song Weihua (2007). Advanced Oxidation Degradation of Diclofenac (IAEA-RC-11882). International Atomic Energy Agency (IAEA), Division of Physical and Chemical Sciences, Vienna (Austria); 191(2),168-179. http://www-naweb.iaea.org/nap/iachem/working_ materials/RC-1188-2-report.pdf.

Eriksson, J., Svanfelt, J., \& Kronberg, L. (2010). A photochemical study of diclofenac and its major transformation products. Photochemistry and Photobiology, 86(3), 528-532. https://doi.org/10.1111/j.1751-1097.2009.00703.x.

Ferrari, B., Paxéus, N., Giudice, R. L., Pollio, A., \& Garric, J. (2003). Ecotoxicological impact of pharmaceuticals found in treated wastewaters: Study of carbamazepine, clofibric acid, and diclofenac. Ecotoxicology and Environmental Safety, 55(3), 359-370. https://doi.org/10.1016/S0147-6513(02 )00082-9.

Garima, K., \& Sindri, B. (2017). NSAIDS in the environment: from emerging problem to green solution. Ann Pharmacol Pharm, 2(14), 1-3 http://remedypublications. com/pharmacology-and-pharmaceutics/articles/pdfs folder/app-v2-id1077.pdf.

Gidal, B. E., Clark, A. M., Anders, B., \& Gilliam, F. (2017). The application of half-life in clinical decision making: comparison of the pharmacokinetics of extended-release topiramate (USL255) and immediate-release topiramate. Epilepsy Research, 129, 26-32. https://doi.org/10.1016/j. eplepsyres.2016.10.020.

Hashim, N., Natarajan, P., \& Ray, A. K. (2014). Intrinsic kinetic study for photocatalytic degradation of diclofenac under UV and visible light. Industrial \& Engineering Chemistry Research, 53(49), 18637-18646. https://doi.org/10.1021 /ie404355k.

Jiménez, C. (2011). Contaminantes orgánicos emergentes en el ambiente: productos farmacéuticos. Revista Lasallista de Investigacion, 8(2), 143-153. https://doi.org/10.1109 /TGRS.2011.2120615.

Keen, O. S., Thurman, E. M., Ferrer, I., Dotson, A. D., \& Linden, K. G. (2013). Dimer formation during UV photolysis of diclofenac. Chemosphere, 93(9), 1948-1956. https://doi. org/10.1016/j.chemosphere.2013.06.079.

Köhler, H.-R., Schwaiger, J., Eikemper, R., Triebskorn, R., Heyd, A., \& Casper, H. (2004). Toxic effects of the non-steroidal anti-inflammatory drug diclofenac. Aquatic Toxicology, 68(2), 151-166. https://doi.org/10.1016/j. aquatox.2004.03.015.

Kovacic, M., Juretic Perisic, D., Biosic, M., Kusic, H., Babic, S., \& Loncaric Bozic, A. (2016). UV photolysis of diclofenac in water; kinetics, degradation pathway and environmental aspects. Environmental Science and Pollution Research, 23(15), 14908-14917. https://doi.org/10.1007/s11356-0166580-x.

Lawrence, J. R., Swerhone, G. D. W., Topp, E., Korber, D. R., Neu, T. R., \& Wassenaar, L. I. (2007). Structural and functional responses of river biofilm communities to the nonsteroidal anti-inflammatory diclofenac. Environmental Toxicology and Chemistry, 26(4), 573-582. https://doi. org/10.1897/06-340R.1.

Lonappan, L., Brar, S. K., Das, R. K., Verma, M., \& Surampalli, R. Y. (2016). Diclofenac and its transformation products: environmental occurrence and toxicity - a review. Environment International, 96, 127-138. https://doi.org/10.1016/j. envint.2016.09.014.

Magureanu, M., Dobrin, D., Bradu, C., Mandache, N. B., \& Parvulescu, V. I. (2015). Removal of the pharmaceutical diclofenac by pulsed corona discharge. National Institute for Lasers, 22nd International Symposiumon Plasma Chemistry - ISPC 2015, p 1-4. Antwerp, Belgium. https://www.ispcconference.org/ispcproc/ispc22/P-III-9-22. pdf.org/ispcproc/ispc22/P-III-9-22.pdf..

Melo, S. R. d. O., Homem-de-Mello, M., Silveira, D., \& Simeoni, L. A. (2014). Advice on degradation products in pharmaceuticals: a toxicological evaluation. PDA Journal of 
Pharmaceutical Science and Technology, 68(3), 221-238. https://doi.org/10.5731/pdajpst.2014.00974.

Memmert, U., Peither, A., Burri, R., Weber, K., Schmidt, T., Sumpter, J. P., \& Hartmann, A. (2013). Diclofenac: new data on chronic toxicity and bioconcentration in fish. Environmental Toxicology and Chemistry, 32(2), 442-452. https://doi.org/10.1002/etc.2085.

Orepesa, A. L. (2008). Disruptores endocrinos en el medio ambiente: Caso del 17 - $\alpha$ - etinil-estradiol. Observatorio Ambiental, 11, 63-76. https://doi.org/10.5209/REV_ OBMD.2008.V11.22427.

Qin, M., Yang, H., Chen, S., Xie, H., \& Guan, J. (2012). Photochemical characteristics of diclofenac and its photodegradation of inclusion complexes with ??-cyclodextrins. Quimica Nova, 35(3), 559-562. https://doi.org/10.1590 /S0100-40422012000300022.

Rainsford, K. D., Kean, W. F., \& Ehrlich, G. E. (2008). Review of the pharmaceutical properties and clinical effects of the topical NSAID formulation, diclofenac epolamine. Current Medical Research and Opinion, 24(10), 2967-2992. https://doi.org/10.1185/03007990802381364.

Salam, L. B., Ilori, M. O., \& Amund, O. O. (2017). Properties, environmental fate and biodegradation of carbazole. 3 Biotech, 7(2). https://doi.org/10.1007/s13205-017-0743-4.
Scott Fogler, H. (2002). Elements of chemical reaction engineering. Chemical engineering science (third., Vol. 42). New Jersey: Prentice Hall Inc.. https://doi.org/10.1016/00092509(87)80130-6.

Vieno, N., Tuhkanen, T., \& Kronberg, L. (2006). Removal of pharmaceuticals in drinking water treatment: effect of chemical coagulation. Environmental Technology, 27(2), 183-192. https://doi.org/10.1080/09593332708618632.

Wang, J., \& Hu, X. (2014). Ecopharmacovigilance: current state, challenges, and opportunities in China. Indian Journal of Pharmacology, 46(1), 13. https://doi.org/10.4103/02537613.125158 .

Zhang, N., Li, J. M., Liu, G. G., Chen, X. L., \& Jiang, K. (2017). Photodegradation of diclofenac in aqueous solution by simulated sunlight irradiation: kinetics, thermodynamics and pathways. Water Science and Technology, 75(9), 21632170. https://doi.org/10.2166/wst.2017.075.

Publisher's Note Springer Nature remains neutral with regard to jurisdictional claims in published maps and institutional affiliations. 